\title{
The Place of Laparoscopic Gastrostomy in the Surgical Armamentarium
}

\author{
Philip Ng Cheng Hin \\ Department Of Surgery, University Hospital Lewisham, London \\ UK
}

\section{Introduction}

Historically, gastrostomy has been performed for centuries and recently with the advent of Laparoscopic surgery, laparoscopic gastrostomy (ref 1) has been added to the options available to surgeons.

Laparoscopic gastrostomy can be considered when other minimally invasive methods such as PEG (Percutaneous Endoscopic Gastrostomy) is not feasible or fails. PEG can be come impossible if the endoscope cannot be introduced, because of physical or functional obstruction. The alternative is to consider PRG (Percutaneous Radiologically Guided) insertion prior to considering open gastrostomy via laparotomy, (LG) Laparoscopic gastrostomy has carved itself an important niche in that respect.

\section{Indications of gastrostomy}

a. Patients requiring Medium or long term feeding

- Starvation

- Swallowing problems, long term neurological conditions

- Chronic problems in children e.g. mucoviscidosis, reflux

- Impassable benign or malignant stricture

b. Decompression of the stomach

c. Gastric access

d. Failure of PEG

e. Failure of PRG

\section{Contra indications}

a. Unfit patients who cannot lie flat.

b. Abdominal access not possible due to previous operations or gross obesity, fixed flexion deformity.

\section{Techniques}

a. Double puncture laparoscopic assisted gastrostomy (ref 2, 4)

Once the abdomen prepped, entry into the peritoneal cavity is performed using any preferred technique through a periumbilical port and the pneumoperitoneum is 
established, the anterior wall of the stomach is identified with certainty, and a second port $(10 \mathrm{~mm})$ is inserted at a convenient point on the anterior abdominal wall. This operative step is greatly assisted by changing the position of the operating table 20 degrees head up. Once the anterior gastric wall is identified, it is firmly grasped using a Babcock forceps and withdrawn slowly through the port site while the abdomen is deflated. (Fig1)

The stomach usually comes easily to be exteriorised through the port site, which is then enlarged.

Two concentric purse strings of 2/0 PDS are inserted on the gastric wall, (fig 2) keeping the needles attached and a small gastrotomy performed using either diathermy or a No 11 blade. (Fig3)

The appropriate size gastrostomy tube or button can then be inserted (Fig 4) and the retaining balloon inflated. The two purse strings are tied securely, creating a small well, and the needles used to attach the stomach wall to the anterior abdominal. Two extra stitches are then used to secure the stomach wall to the anterior abdominal wall as in a 4-point fixation. The correct intragastric position of the feeding tube is then verified by reinflating the peritoneal cavity slowly to $5 \mathrm{~mm} \mathrm{Hg}$. (Fig 5) The patency and absence of leakage is then tested with the laparoscope in situ and if satisfactory, the entry port is closed after deflation. Feeding can start immediately at $30-\mathrm{ml} /$ hour increasing to $60 \mathrm{ml} / \mathrm{hr}$, then full feed. Local anaesthetic is infiltrated into the wounds as required.

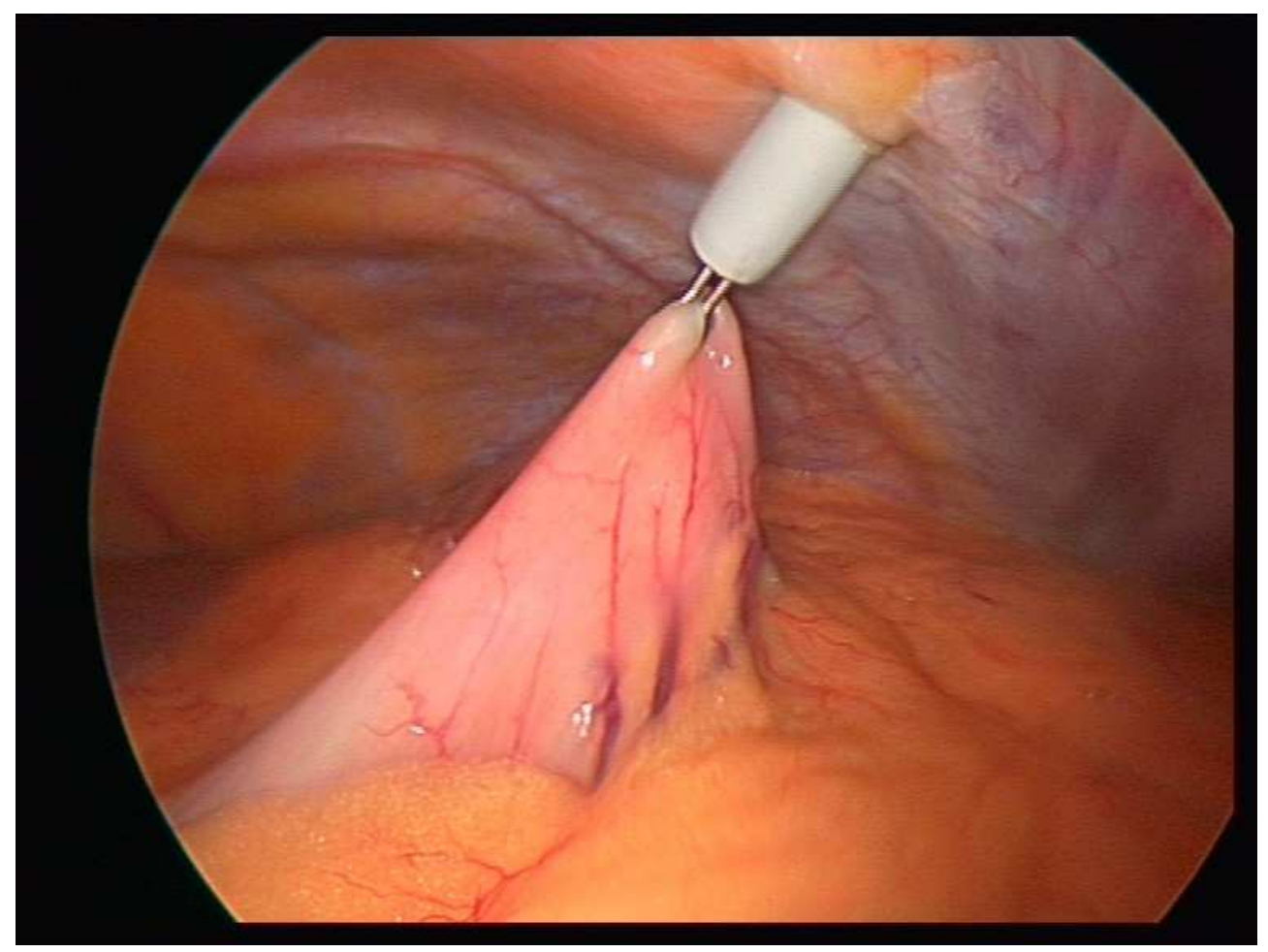

Fig. 1. 


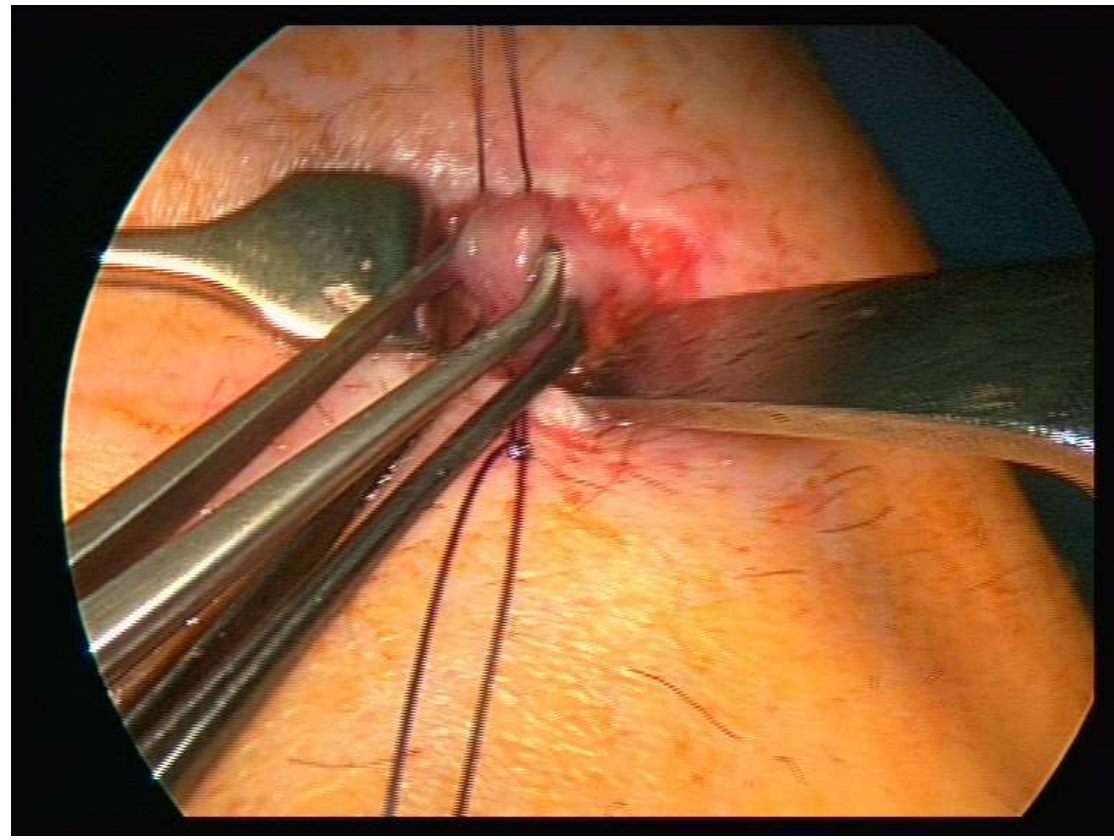

Fig. 2.

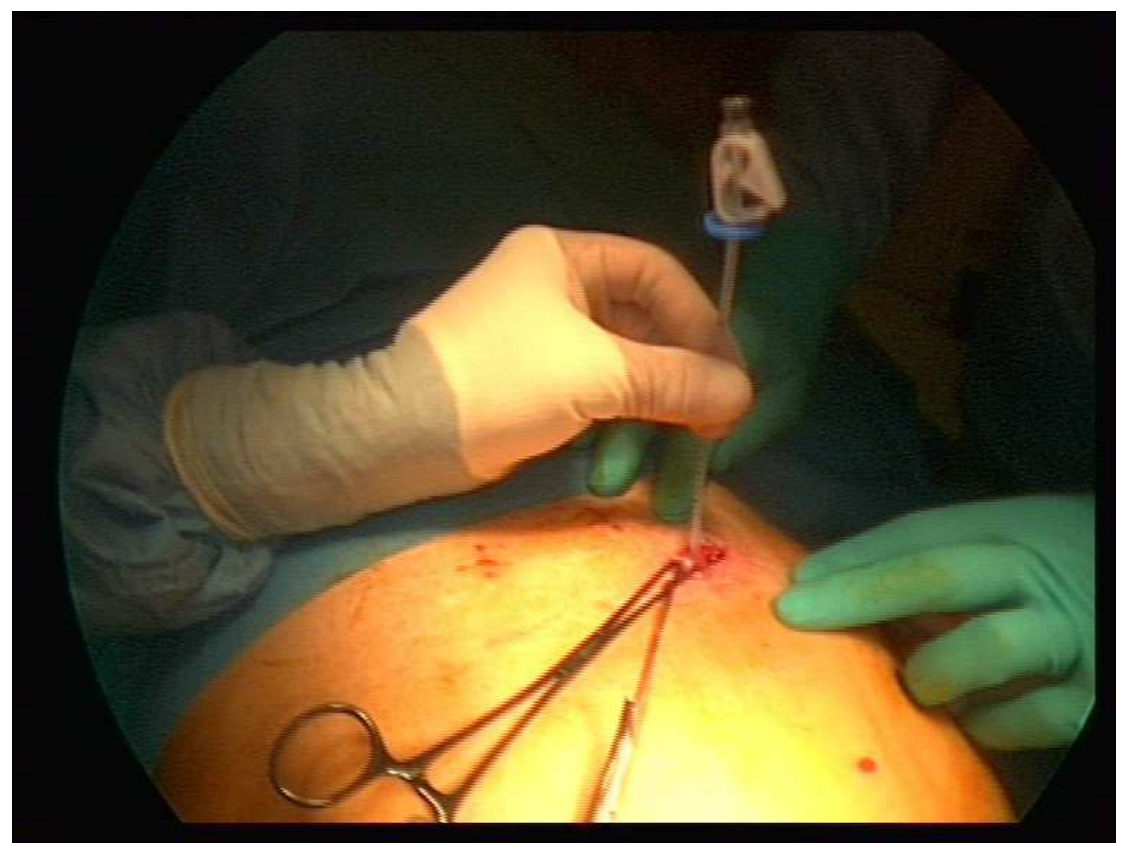

Fig. 3. 


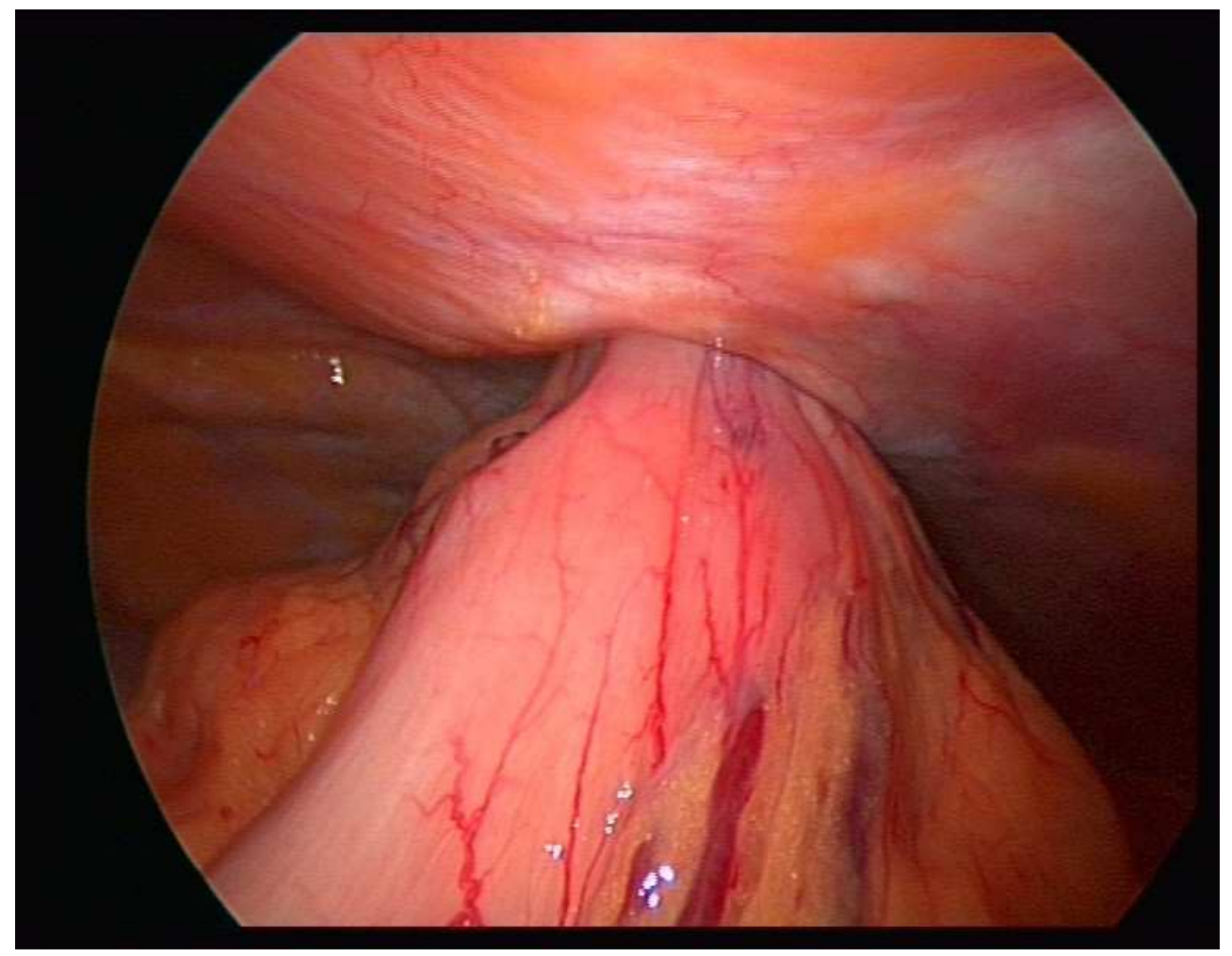

Fig. 4.

\section{b. Single puncture laparoscopic assisted gastrostomy}

In the Single puncture technique, the site of the gastrostomy is chosen first. Either local anaesthetic is infiltrated or a general anaesthetic administered to allow access to the abdominal cavity is achieved. A $10 \mathrm{~mm}$ trocar is used to carry a $10 \mathrm{~mm}$ scope and an operating laparoscope with an instrument channel is used. After identification of the anterior gastric wall, a forceps is used to grasp the anterior gastric wall, which is then exteriorised as the abdomen is deflated. The gastrotomy can be performed between two concentric purse strings as in the double puncture technique, its position inside the stomach ascertained and the tube secured in the same manner.

\section{c. Button laparoscopic gastrostomy}

The technique here is also similar to the gastrostomy technique substituting the button for the gastrostomy tube (Ref 5). A useful measure is to first insert a Foley catheter into the gastrotomy and mark the level (Fig5) in order to measure the exact size of button.

Once the button gastrostomy tube has been inserted, the purse strings tied, and the balloon inflated, the correct intragastric position can be verified by reinflating the abdomen to a pressure of $5 \mathrm{~mm} \mathrm{Hg}$ and tugging on the tube while checking the position under direct vision.(fig6) 


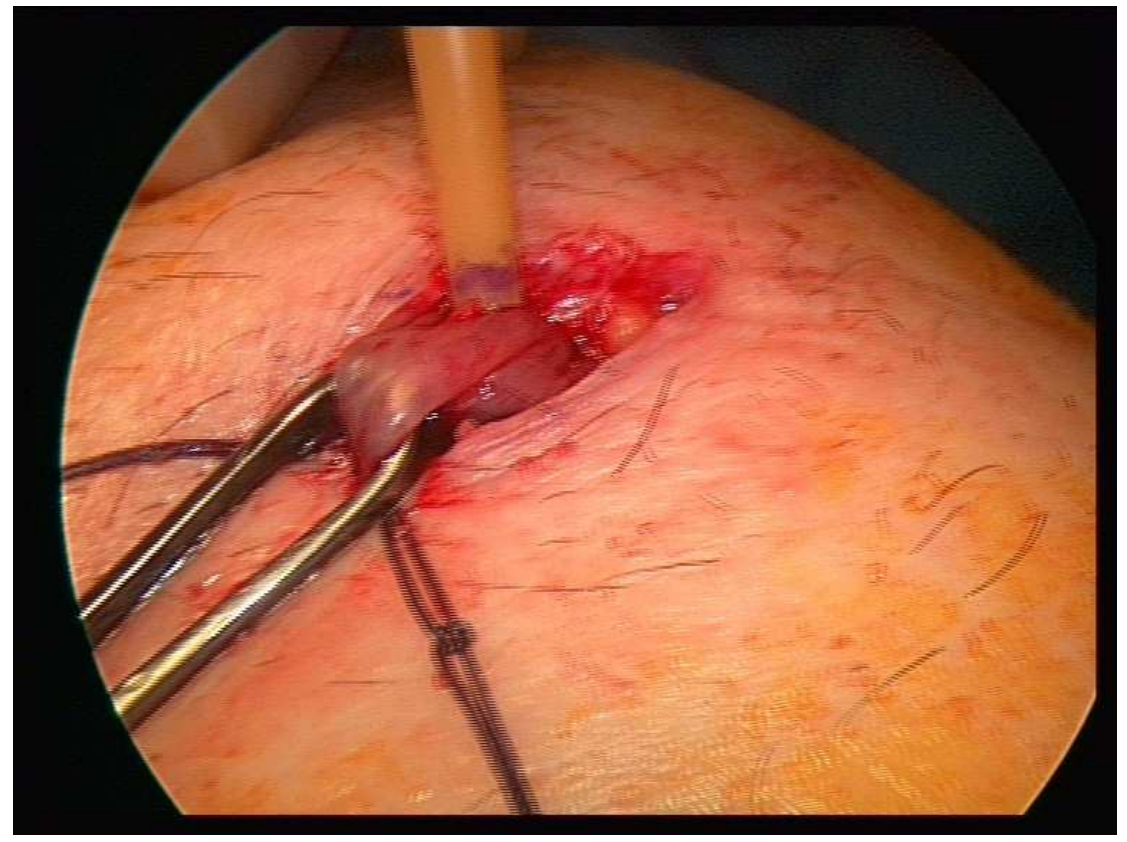

Fig. 5.

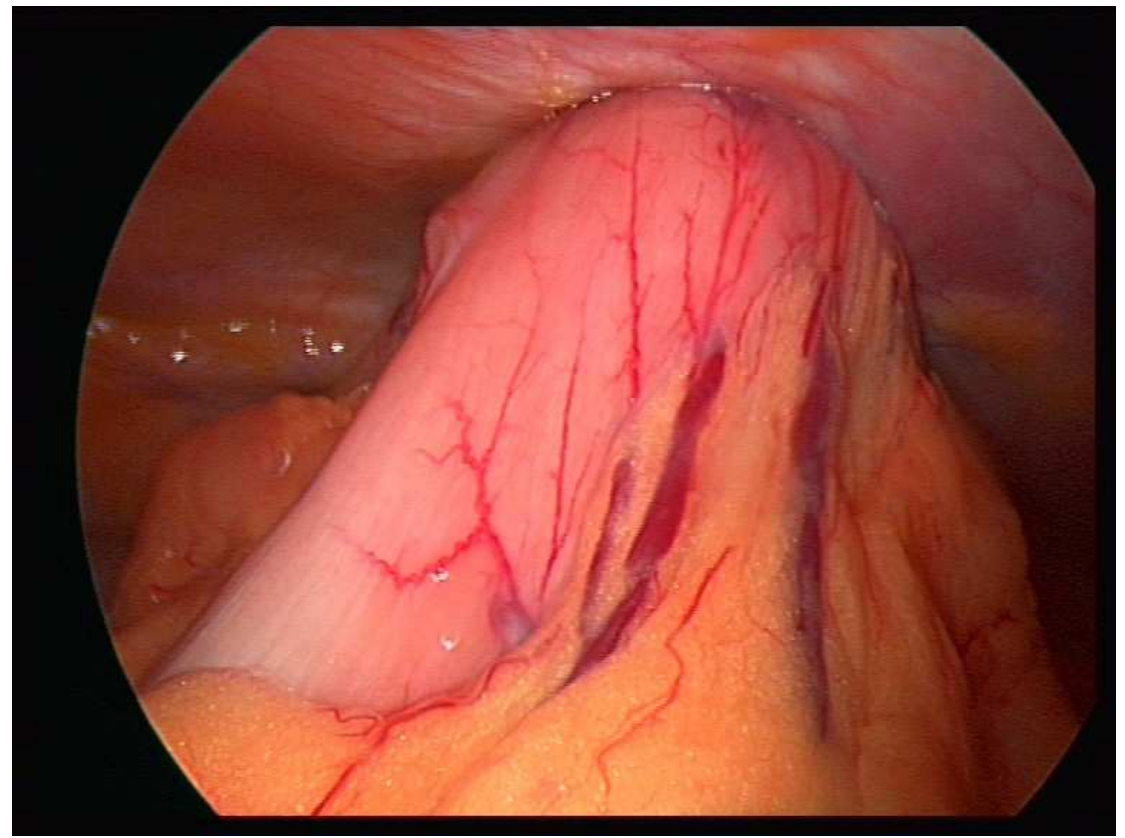

Fig. 6. 


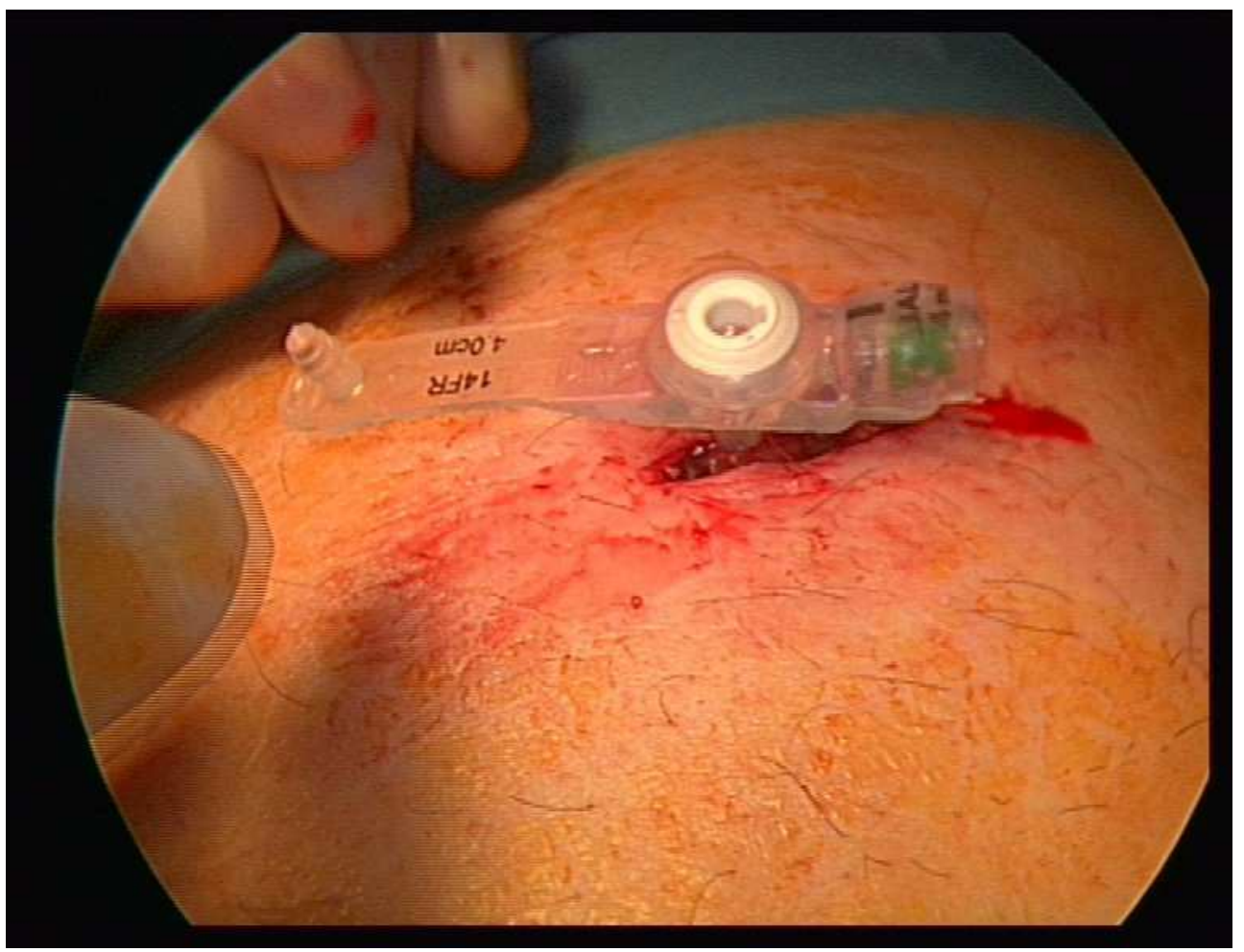

Fig. 7.

\section{Anaesthetic}

Local infiltration, Loco regional or general can be used

a. General anaesthetic with or without muscle relaxant although use of the latter facilitates rapid exploration and identification of intra abdominal organs.

b. Loco regional

c. Spinal anaesthetic where indicated

d. Local and sedation

e. Where neither General nor loco regional is indicated simple local anaesthetic can be used with success after careful infiltration of anaesthetic such as Xylocaine 1\% in the tissues prior to cutting. Sedation is useful to keep the patient compliant. A preset pressure of $5-10 \mathrm{~mm} \mathrm{Hg}$ is adequate for laparoscopic visualisation.

f. Local only. When all other options cannot be used just simple infiltration can be used in thin patients.

\section{Patient position}

The ideal patient position is flat on the operating table with a 20 degree head up tilt. Patients who have problems straightening their spine may prove difficult to access. Patients with 
fixed flexion deformity of the hip may prove difficult to scope, in which case, a 20 degree left side up tilt table rotation may prove useful.

\section{Consent}

The 30-day mortality in most studies indicates a mortality of $15-25 \%$ which many argue is not directly related to procedure but to the general patient debility. This however must be included in the consent as well as the risks of infection, bleeding organ injury and leakage both peritubular or intraperitoneal, aspiration pneumonia.

\section{Post operative}

Care is taken to ensure the secure fixation of the gastrostomy tubes and the correct intragastric positioning. Should there be any doubt, feeding is interrupted and the position can be rapidly checked by another contrast study. Tube dressings are verified daily and if in doubt as to the patency and position they can be verified specially in restless patients. Nursing the patients in the semi- sitting position may prevent pneumonia in these debilitated patients.

\section{Complications}

The main complications of Gastrostomy tube placement are:

\section{EARLY}

1. Misplacement.

Using the verification steps as described should prevent any inadvertent placement of the tubes. Before feeding the intragastric position and absence of leakage must be confirmed preferably by a contrast study.

2. Leakage

This is a troublesome complication and can be prevented and treated by judicious choice of the size othe tube which should be a snug fit. However, in malnourished patients wit severe hypoalbuminemia, the gastrotomy sites can break down, hence the attention paid to insert a wide double purse string.

3. Infection

Infection of the stoma site can be treated with Metronidazole ointment and daily dressings.

4. Peristomal skin irritation.

This is due to leakage of acid stomach contents. A barrier dressing of Duoderm is helpful in shielding the skin from the inevitable spillage.

\section{LATE}

Later complications include tube slippage, patient pulling the tube out or inadvertent displacement. Once a track has been established, it is a simple matter of replacing the tube with a similar size and type. Once this is achieved, a new contrast study is mandatory to confirm the intragastric position and absence of leakage before resuming feeds.

\section{MORTALITY}

The mortality has been described as varying up to $12 \%$ (Ref6). 


\section{References}

[1] Nah SA, Narayanaswamy B, Eaton S, Coppi PD, Kiely EM, Curry JI, Drake DP, Barnacle AM, Roebuck DJ, Pierro A. Gastrostomy insertion in children : Percutaneous endoscopic or Percutaneous image guided? J Pediatr Surg. 2010 Jun; 45(6): 1153-8. Fewer PEG patients (28\%) had complications than did IG $(47 \%)(\mathrm{P}=.001)$

[2] Gossage JA, Cho A, Ng PC Technique. Ann R Coll Surg Engl. 2007 Jul; 89(5): 530

[3] Ng PC Single-puncture laparoscopic-assisted gastrostomy. J Laparoendosc Adv Surg Tech A. 1997 Jun; 7(3): 173-5. PMID: 9448129Ng PC

[4] Laparoscopic gastrostomy: a simple way to feed. Surg Laparosc Endosc. 1994 Dec; 4(6): 463-4. PMID:7866620

[5] R. Durai, P. C. H. Ng Simple Technique of Selecting the Correct Feeding Gastrostomy Button. Acta Chir Belg, 2011, 111, 000-000

[6] Pruthi D, Duerksen DR, Singh H. The practice of gastrostomy tube placement across a Canadian regional health authority. Am J Gastroenterol. 2010 Jul;105(7):1541-50. Epub 2010 Jan 26. 


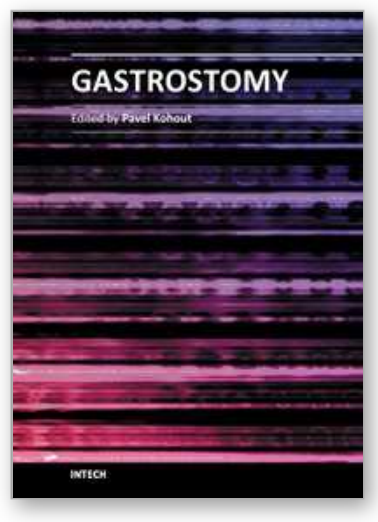

\author{
Gastrostomy \\ Edited by Dr. Pavel Kohout
}

ISBN 978-953-307-365-1

Hard cover, 152 pages

Publisher InTech

Published online 02, December, 2011

Published in print edition December, 2011

The gastrostomy placement is a method of providing nutrition to the patients who are unable to eat. In this book you can find chapters focused on the use of gastrostomy in children, patients with neurological impairment and patients with head and neck tumours. Home enteral nutrition is suitable for all of these groups of patients and is far easier with gastrostomy. The new indications (especially in very young children) required new techniques such as: laparoscopic gastrostomy, laparoscopy assisted endoscopic gastrostomy with/without fundoplication, ultrasonography assisted gastronomy. All information about these techniques can be found in this book. This book does not serve as a basic textbook, but as an interesting reading material and as an aid for physicians who are already familiar with the indication for gastrostomy and want to know more.

\title{
How to reference
}

In order to correctly reference this scholarly work, feel free to copy and paste the following:

Philip Ng Cheng Hin (2011). The Place of Laparoscopic Gastrostomy in the Surgical Armamentarium, Gastrostomy, Dr. Pavel Kohout (Ed.), ISBN: 978-953-307-365-1, InTech, Available from: http://www.intechopen.com/books/gastrostomy/the-place-of-laparoscopic-gastrostomy-in-the-surgicalarmamentarium

\section{INTECH}

open science | open minds

\section{InTech Europe}

University Campus STeP Ri Slavka Krautzeka 83/A 51000 Rijeka, Croatia Phone: +385 (51) 770447 Fax: +385 (51) 686166 www.intechopen.com

\section{InTech China}

Unit 405, Office Block, Hotel Equatorial Shanghai No.65, Yan An Road (West), Shanghai, 200040, China 中国上海市延安西路65号上海国际贵都大饭店办公楼405单元 Phone: +86-21-62489820

Fax: +86-21-62489821 
(C) 2011 The Author(s). Licensee IntechOpen. This is an open access article distributed under the terms of the Creative Commons Attribution 3.0 License, which permits unrestricted use, distribution, and reproduction in any medium, provided the original work is properly cited. 